\begin{tabular}{ccc}
\hline International Journal of Engineering \& Technology, $7(2.24)(2018) 200-204$ \\
International Journal of Engineering \& Technology \\
SPC \\
Website: www.sciencepubco.com/index.php/IJET \\
Research paper
\end{tabular}

\title{
Control of Third Order Processes Using Optimized Synthesis PI Controller
}

\author{
G. Suganya ${ }^{1}$, E. Govinda Kumar ${ }^{2 *}$ \\ ${ }^{1}$ Department of Computer Science and Engineering, Karpagam College of Engineering, Coimbatore-32. \\ ${ }^{2}$ Department of Electronics and Instrumentation Engineering, Karpagam College of Engineering, Coimbatore-32. \\ *Corresponding author E-mail: egovindakumar@gmail.com
}

\begin{abstract}
In closed loop system with PI controller, the most and severe problem is peak overshoot minimization in the closed loop response and tuning the proportional plus integral (PI) controller parameters. This paper deals with the two different tuning methods for obtain the PI controller settings. These methods are used to tune the parameters of PI controller and the closed loop performances of two methods are analyzed for the control of third order processes. From the closed loop responses, the time responses are move to unstable characteristics and the process variables are oscillates due to PI parameters are tuned using Ziegler-Nichols method and direct synthesis method respectively. The control loop performance of the control of third order process is improved with optimized parameters of PI controller. In direct synthesis method, the variable parameter of PI controller is obtained with Genetic algorithm. The controller parameter of PI controller is obtained from optimized variable parameters and results are reveals that the performance of closed loop is enhanced with the elimination of peak overshoot and minimization of oscillation levels in the process variables. Simulation results are confirmation that the proposed design method is better to the Ziegler-Nichols method and direct synthesis method. Furthermore, the proposed method was applied to the control of two different categories of third order processes.
\end{abstract}

Keywords: PI Controllers; Ziegler-Nichols Method; Direct Synthesis Method; Third Order Process; Genetic Algorithm; Optimized Controller

\section{Introduction}

The proportional-integral (PI)/ proportional - intergral-derivative (PID) controller is one of the most standard algorithms in process control industry [1]. It is an efficacious controller and designing method is not complex. The PI/PID parameters need to be tuned properly and it is most important issue in PI/PID controller design. The number of methods has been reported to tuning the PI/PID controller parameters. The Ziegler-Nichols methods for tuning PI/PID controller have been widely used and it is very important [2]. The Ziegler-Nichols open loop and closed loop methods are still common methods for tuning the parameters of PID controller. This work deals with control of third order system with PI controller and the parameters of PI controller are tuned using ZieglerNichols closed loop method.

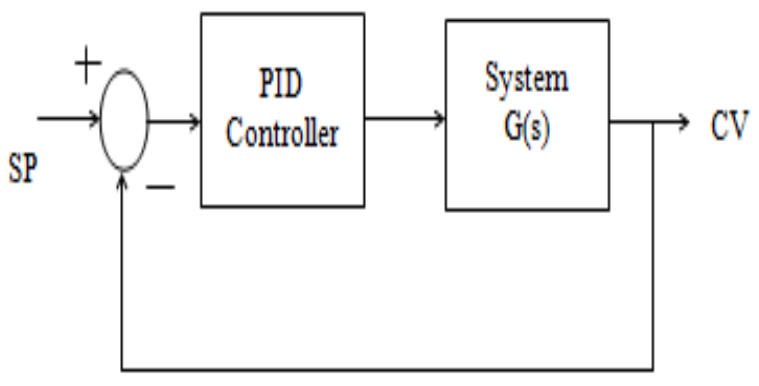

Fig. 1: A feedback system
In feedback system, the gain values of I and D are set to be zero and by varying the parameter gradually until the time response produce a sustain oscillations. From the sustained output, calculate the period of the oscillation (ultimate period) and the resultant value of $P$ is the ultimate gain value. Using the Ziegler-Nichols closed loop method, the parameters of PI/PID controller are determined by using the ultimate period and gain values. The closed loop step responses of certain third order system have oscillations when PI controller is used. The values of ultimate gain and ultimate period are the controller parameters of PID controller. This ultimate gain values are calculated from the step response when sustained oscillations are present. So, the closed loop response has oscillations due to PID controller parameters that are obtained from the ultimate gain and ultimate period.

In recently, the PID controller theory for nonlinear uncertain systems, the global stability and asymptotic regulation of the closedloop control systems are obtained by a simple and analytic design method for the controller parameters [3]. In recent literature, the PI controller can stabilize propagating wave segments in excitable media to a desired size [4]. On PI-controller, the adjustments of PI controller parameters are used for a rolling mill drive control. It shows that, the quality improvement of transient response of speed and current control loops [5].

The direct synthesis method is used and determines the parameters of PI controllers and it is used for the control of wide variety of processes, inclusion of delay time with first-order system, secondorder system, an integrator system and non-minimum phase system. An internal model control and standard direct synthesis methods are provides better disturbance rejection [6]. Form closed-loop data, the direct synthesis method is used to tune the PI controller parameters. It shown that, model free direct synthesis method is more effective than the model-based design methods [7]. 
The computationally intelligent methods like bacterial foraging optimization (BFO) and particle swarm optimization (PSO) are applied for the tuning of PI controller with variable parameters. It has been reduced the peak overshoot and peak undershoot for control of multi area interconnected power system [8]. Recently [9], the elimination of peak overshoot is obtained by using the conventional PID controller with cascading of Lead compensator. The paper is organized as follows. Section two presents the basics of PI controller and its terminologies. Section three is about designing of PI controller for third order system using ZieglerNichols method and direct synthesis method. The results of conventional PI controller for third order processes are discussed in Section four. Section five deals that the proposed optimized direct synthesis PI controller are applied for the control third order process. Conclusion is drawn in Section six.

\section{Review of PI controller}

The control signal of proportional $(\mathrm{P})$ control action is proportional to the error signal and $\mathrm{P}$ controller is represented as [10],

$u(t)=K_{P} e(t)$

The PI controller action or signal is represented as below [10],

$u(t)=K_{P}\left(e(t)+\frac{1}{T_{i}} \int e(t) d t\right)$

The proportional gain $\left(K_{p}\right)$ and integral time constant $\left(T_{i}\right)$ are used to determine the integral gain or constant $\left(K_{i}\right)$ and it is represented as, $K_{i}=K_{p} / T_{i}$

\section{Designing of PI controller using Ziegler- Nichols and Direct Synthesis Methods}

The transfer function of third order system is represented as,

$$
G(\mathrm{~s})=\frac{K}{a_{3} s^{3}+a_{2} s^{2}+a_{1} s+a_{0}}
$$

Where, $K$ is the system gain and $a_{0}, a_{1}, a_{2}, a_{3}$ are the coefficients of denominator polynomial equation of $G(s)$.

\subsection{Tuning of Ziegler-Nichols Method}

The parameter of above PI controller is obtained by using ZieglerNichols closed loop method [11]. The tuning equations of PI controller are given below. The proportional gain of PID controller is [2],

$$
K_{p}=0.45 K_{u}
$$

The integral and differential time constants are obtained using the below equations [2],

$$
T_{i}=0.833 P_{u}
$$

Using Eq. (2) we can obtain the final form of PI controller equation.

\subsection{The direct synthesis based PI Controller Design}

The closed loop feedback system is shown in Fig. 2 and $G_{C}$ and $G_{P}$ are controller and process transfer functions.

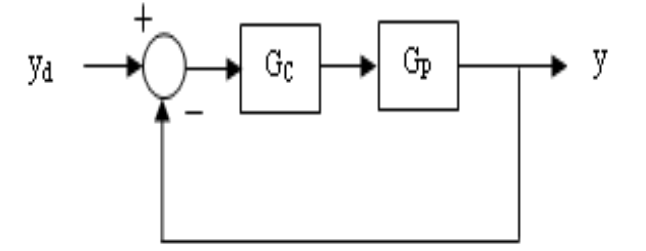

Fig. 2: The closed system with unity feedback.

The overall transfer function of the above system is,

$$
\frac{y}{y_{d}}=\frac{G_{C} G_{P}}{1+G_{C} G_{P}}
$$

The above transfer function is represents that the set-point tracking functions. The controller transfer function is used to manipulate the input variable. The controller transfer function is obtained by rearranging the above Eq. (6) is,

$$
G_{C}=\frac{\frac{y}{y_{d}}}{G_{P}\left(1-\frac{y}{y_{d}}\right)}
$$

Consider the closed loop response of final value is to be first order decay [11]. Then,

$$
\frac{y}{y_{d}}=\frac{1}{\tau_{c} s+1}
$$

The controller equation form is obtained by considering the above assumption.

$$
G_{C}=\frac{1}{G_{P}} \cdot \frac{1}{\tau_{c} s}
$$

Using Eq. (3) in Eq. (9),

$$
G_{c}(s)=\frac{a_{1}}{K \tau_{c}}\left(1+\frac{a_{0}}{a_{1} s}+\frac{a_{2} s}{a_{1}}+\frac{a_{3} s^{2}}{a_{1}}\right)
$$

Apply the Laplace transform on PID controller equation with zero initial condition, the controller expression is,

$G_{c}(s)=K_{p}\left(1+\frac{1}{\tau_{i} s}\right)$

Compare the coefficients of the above Eq. 10 and Eq. 11. From the comparison the controller tuning expressions are,

$$
\begin{aligned}
& K_{p}=\frac{a_{1}}{K \tau_{c}} \\
& K_{i}=\frac{a_{0}}{K \tau_{c}}
\end{aligned}
$$

\section{Results and Discussion}

The transfer function of third order system $\mathrm{G}(\mathrm{s})$ is,

$$
G(\mathrm{~s})=\frac{K}{a_{3} s^{3}+a_{2} s^{2}+a_{1} s+a_{0}}
$$

The conventional PI controller parameters are tuned by using the Eq. (4) and Eq. (5). The PI Controller parameters of direct synthesis method are obtained by using Eq. (12) and Eq. (13) with parameters of process transfer function. 


\subsection{Conventional PI controller performance of third order processes}

The coefficients of denominator polynomial expression of the above transfer function are $a_{3}, a_{2}, a_{1}$ and $a_{0}$. The different third order transfer functions are used based on the values of coefficients (case 1) and it is tabulated in Table 1. The determined ultimate gain $\left(K_{u}\right)$ and ultimate period $\left(P_{u}\right)$ are tabulated for different process transfer functions. Also, the controller settings of PI controller are given in Table 1 and these values are obtained by using the Ziegler-Nichols closed loop method [2].

Table 1: Processes parameters and PI controller setting (Case 1)

\begin{tabular}{|c|c|c|c|c|}
\hline Coefficients & Values & $\begin{array}{c}\mathrm{K}_{\mathrm{u}} \text { and } \\
\mathrm{P}_{\mathrm{u}}\end{array}$ & $\begin{array}{l}\text { Magnitude } \\
\text { of sustain } \\
\text { oscillations }\end{array}$ & $\begin{array}{l}\text { Parameters } \\
\text { of PI con- } \\
\text { troller }\end{array}$ \\
\hline$\left(\mathrm{a}_{0}, \mathrm{a}_{1}, \mathrm{a}_{2}, \mathrm{a}_{3}\right)$ & $\begin{array}{c}(1,1,1.5, \\
1)\end{array}$ & $\begin{array}{c}0.5 \\
6.2833\end{array}$ & 0.6 & $\begin{array}{l}\mathrm{K}_{\mathrm{p}}=0.2250 \\
\mathrm{~K}_{\mathrm{i}}=0.0430\end{array}$ \\
\hline$\left(\mathrm{a}_{0}, \mathrm{a}_{1}, \mathrm{a}_{2}, \mathrm{a}_{3}\right)$ & $\begin{array}{c}(1,1,2, \\
1)\end{array}$ & $\begin{array}{c}1, \\
6.2381\end{array}$ & 0.9 & $\begin{array}{c}\mathrm{K}_{\mathrm{p}}=0.45 \\
\mathrm{~K}_{\mathrm{i}}=0.0866\end{array}$ \\
\hline$\left(\mathrm{a}_{0}, \mathrm{a}_{1}, \mathrm{a}_{2}, \mathrm{a}_{3}\right)$ & $\begin{array}{c}(1,3,3, \\
1)\end{array}$ & $\begin{array}{c}2, \\
6.299\end{array}$ & 1.25 & $\begin{array}{c}\mathrm{K}_{\mathrm{p}}=0.9 \\
\mathrm{~K}_{\mathrm{i}}=0.1715\end{array}$ \\
\hline$\left(\mathrm{a}_{0}, \mathrm{a}_{1}, \mathrm{a}_{2}, \mathrm{a}_{3}\right)$ & $\begin{array}{c}(1,1,4, \\
1)\end{array}$ & $\begin{array}{c}3, \\
6.2832 \\
\end{array}$ & 1.42 & $\begin{array}{c}\mathrm{K}_{\mathrm{p}}=1.35 \\
\mathrm{~K}_{\mathrm{i}}=0.2579\end{array}$ \\
\hline$\left(\mathrm{a}_{0}, \mathrm{a}_{1}, \mathrm{a}_{2}, \mathrm{a}_{3}\right)$ & $\begin{array}{c}(1,1,5, \\
1)\end{array}$ & $\begin{array}{c}4, \\
6.2798\end{array}$ & 1.58 & $\begin{array}{c}\mathrm{K}_{\mathrm{p}}=1.8 \\
\mathrm{~K}_{\mathrm{i}}=0.3441\end{array}$ \\
\hline
\end{tabular}

The above PI controller parameters are used to control the third order processes. The unit step responses of closed system with PI controllers are shown in Fig. 3.

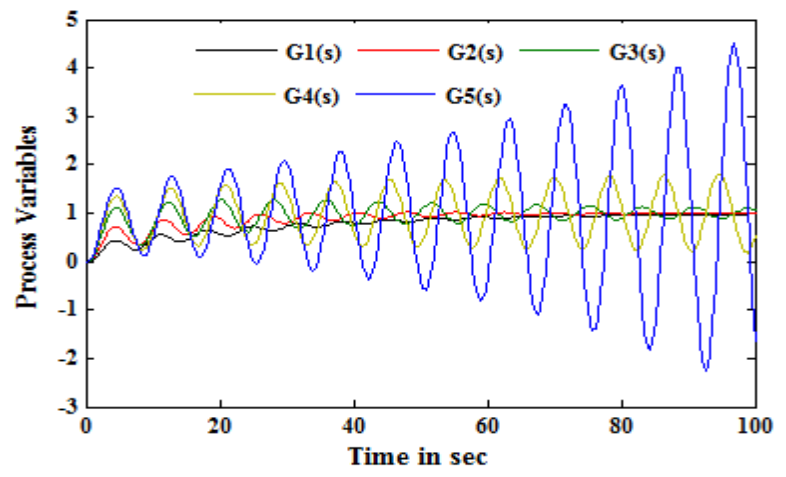

Fig. 3: Response of PI controller (Ziegler-Nichols Method)

From the above results, we can identify the oscillations are present and also the system behavior is changed from stable to unstable characteristics. The main objective is to eliminate the oscillating behavior and also enhance the closed loop performance.

Further analysis of PI controller performance, the coefficient of the denominator polynomial equation of a third order systems (case 2) are changed and tabulated in Table 2. The values of ultimate gain $\left(K_{u}\right)$, ultimate period $\left(P_{u}\right)$, magnitude of sustained oscillation and the PI controller parameters are given in below table.

Table 2: Processes parameters and PI controller settings (case 2)

\begin{tabular}{|c|c|c|c|c|}
\hline Coefficients & Values & $\begin{array}{c}\mathrm{Ku} \text { and } \\
\mathrm{Pu}\end{array}$ & $\begin{array}{l}\text { Magnitude } \\
\text { of sustain } \\
\text { oscillations }\end{array}$ & $\begin{array}{c}\text { Parameters } \\
\text { of PI con- } \\
\text { troller }\end{array}$ \\
\hline$\left(\mathrm{a}_{0}, \mathrm{a}_{1}, \mathrm{a}_{2}, \mathrm{a}_{3}\right)$ & $\begin{array}{c}(1,1.5,1, \\
1)\end{array}$ & $\begin{array}{c}0.5, \\
5.1407\end{array}$ & 0.54 & $\begin{array}{l}\mathrm{K}_{\mathrm{p}}=0.2250 \\
\mathrm{~K}_{\mathrm{i}}=0.0525\end{array}$ \\
\hline$\left(\mathrm{a}_{0}, \mathrm{a}_{1}, \mathrm{a}_{2}, \mathrm{a}_{3}\right)$ & $\begin{array}{c}(1,2,1 \\
1)\end{array}$ & $\begin{array}{c}1, \\
4.4558\end{array}$ & 0.77 & $\begin{array}{l}\mathrm{K}_{\mathrm{p}}=0.45 \\
\mathrm{~K}_{\mathrm{i}}=0.1212\end{array}$ \\
\hline$\left(\mathrm{a}_{0}, \mathrm{a}_{1}, \mathrm{a}_{2}, \mathrm{a}_{3}\right)$ & $\begin{array}{c}(1,3,1, \\
1)\end{array}$ & $\begin{array}{c}2, \\
3.6195 \\
\end{array}$ & 1 & $\begin{array}{l}\mathrm{K}_{\mathrm{p}}=0.9 \\
\mathrm{~K}_{\mathrm{i}}=0.2985\end{array}$ \\
\hline$\left(a_{0}, a_{1}, a_{2}, a_{3}\right)$ & $\begin{array}{c}(1,4,1, \\
1)\end{array}$ & $\begin{array}{c}3, \\
3.1202 \\
\end{array}$ & 1.06 & $\begin{array}{l}\mathrm{K}_{\mathrm{p}}=1.35 \\
\mathrm{~K}_{\mathrm{i}}=0.5177\end{array}$ \\
\hline$\left(\mathrm{a}_{0}, \mathrm{a}_{1}, \mathrm{a}_{2}, \mathrm{a}_{3}\right)$ & $\begin{array}{c}(1,5,1 \\
1)\end{array}$ & $\begin{array}{c}4, \\
2.7898 \\
\end{array}$ & 1.12 & $\begin{array}{l}\mathrm{K}_{\mathrm{p}}=1.8 \\
\mathrm{~K}_{\mathrm{i}}=0.7740\end{array}$ \\
\hline
\end{tabular}

The above processes (case 2) are considered and tune the PI controller parameters using Ziegler-Nichols closed loop method [2]. These values are tabulated and it is used for the control the third order processes. Fig. 4 shows that the unit step response of closed system with PI controller.

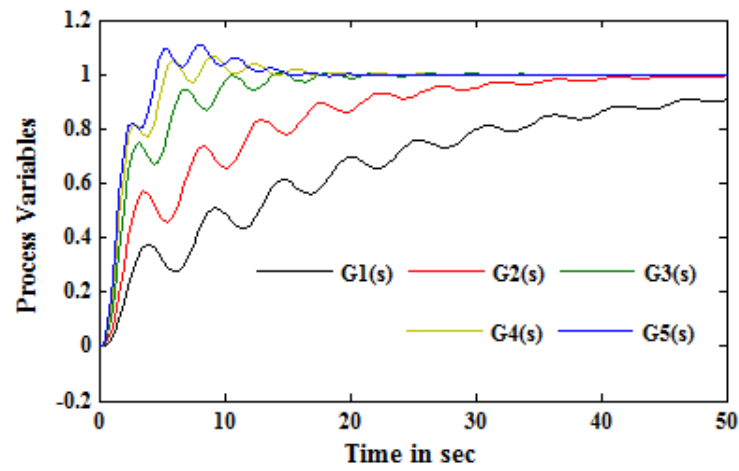

Fig. 4: Response of PI controller (Ziegler-Nichols Method)

From the above simulated responses, we can identify the oscillations are present and also settling time is increased. The closed response of the system $G_{l}(s)$ is not reaches the desired value. The main objective is to minimize the oscillating behavior and also enhance the closed loop performance.

\subsection{Performance of direct synthesis method for third order processes}

The Table 1 and Table 2 process parameters are considered and tune the PI controller parameters using direct synthesis method [11]. These process parameters (case 1) are used for tuning the PI controller parameters and the evaluated parameters are tabulated in Table 3 and Table 4. Theses controller parameters are used for the control the third order processes. The value of $\tau_{c}$ is initially considered as 1 , the closed loop response of third order processes are unstable characteristics. For primarily aiming is enhance the closed loop response, the value of $\tau_{c}$ is gradually increases. From the simulation results, the closed response changes from unstable to stable characteristics. Fig. 5 shows that the unit step response of PI controller setting with the value of $\tau_{c}$ is 10 .

Table 3: Processes parameters and PI controller setting (case 1)

\begin{tabular}{c|c|c|c}
\hline Coefficients & Values & $\begin{array}{c}\text { Parameters of PI } \\
\text { controller } \\
\left(\tau_{c}=1\right)\end{array}$ & $\begin{array}{c}\text { Parameters of PI } \\
\text { controller } \\
\left(\tau_{c}=10\right)\end{array}$ \\
\hline$\left(\mathrm{a}_{0}, \mathrm{a}_{1}, \mathrm{a}_{2}, \mathrm{a}_{3)}\right.$ & $(1,1,1.5$, & $\mathrm{K}_{\mathrm{p}}=1$ & $\mathrm{~K}_{\mathrm{p}}=0.05$ \\
$\mathrm{~K}_{\mathrm{i}}=1$ & $\mathrm{~K}_{\mathrm{i}}=0.05$ \\
\hline$\left(\mathrm{a}_{0}, \mathrm{a}_{1}, \mathrm{a}_{2}, \mathrm{a}_{3)}\right.$ & $(1,1,2,1)$ & $\mathrm{K}_{\mathrm{p}}=1$ & $\mathrm{~K}_{\mathrm{p}}=0.05$ \\
\hline$\left(\mathrm{K}_{0}, \mathrm{a}_{1}, \mathrm{a}_{2}, \mathrm{a}_{3)}\right.$ & $(1,3,3,1)$ & $\mathrm{K}_{\mathrm{p}}=3$ & $\mathrm{~K}_{\mathrm{i}}=0.05$ \\
\hline$\left(\mathrm{a}_{0}, \mathrm{a}_{1}, \mathrm{a}_{2}, \mathrm{a}_{3)}\right.$ & $(1,1,4,1)$ & $\mathrm{K}_{\mathrm{i}}=1$ & $\mathrm{~K}_{\mathrm{p}}=0.15$ \\
\hline$\left(\mathrm{a}_{0}, \mathrm{a}_{1}, \mathrm{a}_{2}, \mathrm{a}_{3)}\right.$ & $(1,1,5,1)$ & $\mathrm{K}_{\mathrm{p}}=1$ & $\mathrm{~K}_{\mathrm{i}}=0.05$ \\
\hline
\end{tabular}




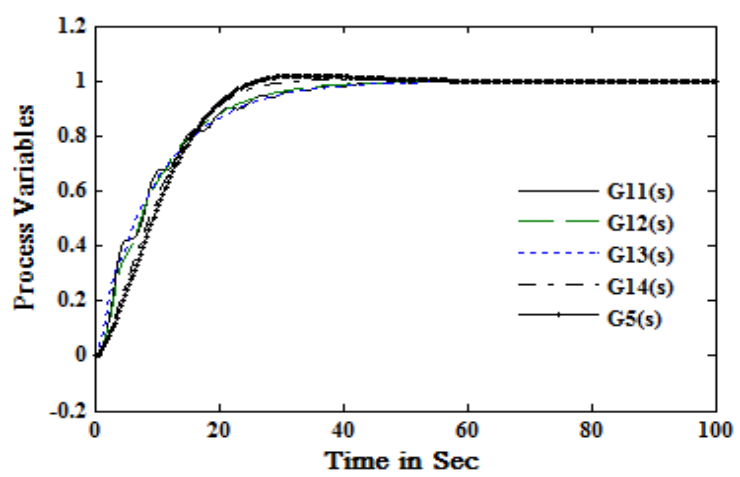

Fig. 5: The closed loop response $\left(\tau_{c}=10\right)$

For the performance evaluation of direct synthesis PI controller, the second categories of third order transfer functions (case 2) are considered. The variable parameter $\tau_{c}$ is considered as 1 , the unstable characteristics are delivered in closed loop system. Recognized from the simulation results, the process variables are reached the desired values for the value of $\tau_{c}$ is 10 .

Table 4: Processes parameters and PI controller settings (case 2)

\begin{tabular}{c|c|c|c}
\hline Coefficients & Values & $\begin{array}{c}\text { Parameters of } \\
\text { PI controller } \\
\left(\tau_{c}=1\right)\end{array}$ & $\begin{array}{c}\text { Parameters of } \\
\text { PI controller } \\
\left(\tau_{c}=10\right)\end{array}$ \\
\hline$\left(\mathrm{a}_{0}, \mathrm{a}_{1}, \mathrm{a}_{2}, \mathrm{a}_{3)}\right.$ & $(1,1.5,1,1)$ & $\begin{array}{c}\mathrm{K}_{\mathrm{p}}=1.5 \\
\mathrm{~K}_{\mathrm{i}}=1\end{array}$ & $\begin{array}{c}\mathrm{K}_{\mathrm{p}}=0.15 \\
\mathrm{~K}_{\mathrm{i}}=0.1\end{array}$ \\
\hline$\left(\mathrm{a}_{0}, \mathrm{a}_{1}, \mathrm{a}_{2}, \mathrm{a}_{3)}\right.$ & $(1,2,1,1)$ & $\begin{array}{c}\mathrm{K}_{\mathrm{p}}=2 \\
\mathrm{~K}_{\mathrm{i}}=1\end{array}$ & $\begin{array}{c}\mathrm{K}_{\mathrm{p}}=0.2 \\
\mathrm{~K}_{\mathrm{i}}=0.1\end{array}$ \\
\hline$\left(\mathrm{a}_{0}, \mathrm{a}_{1}, \mathrm{a}_{2}, \mathrm{a}_{3)}\right.$ & $(1,3,1,1)$ & $\mathrm{K}_{\mathrm{p}}=3$ & $\mathrm{~K}_{\mathrm{p}}=1.3$ \\
\hline$\left(\mathrm{a}_{0}, \mathrm{a}_{1}, \mathrm{a}_{2}, \mathrm{a}_{3)}\right.$ & $(1,4,1,1)$ & $\mathrm{K}_{\mathrm{p}}=4$ & $\mathrm{~K}_{\mathrm{i}}=0.1$ \\
\hline$\left(\mathrm{a}_{0}, \mathrm{a}_{1}, \mathrm{a}_{2}, \mathrm{a}_{3)}\right.$ & $(1,5,1,1)$ & $\mathrm{K}_{\mathrm{i}}=1$ & $\mathrm{~K}_{\mathrm{p}}=0.4$ \\
$\mathrm{~K}_{\mathrm{p}}=0.1$ \\
\hline
\end{tabular}

The above controller parameters are used to control the third order processes. The variable parameter $\tau_{c}$ is 10 and closed loop response is shown in Fig. 6.

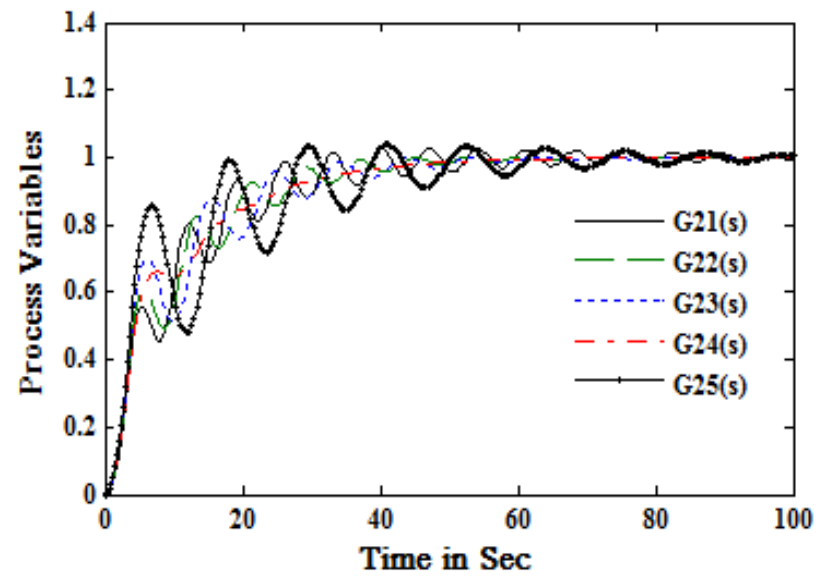

Fig. 6: The closed loop response $\left(\tau_{c}=10\right)$

From Fig. 6, the closed loop response of $\mathrm{G}_{35}(\mathrm{~s}), \mathrm{G}_{45}(\mathrm{~s})$ and $\mathrm{G}_{25}(\mathrm{~s})$ are oscillates around the set-point value. This oscillatory variables are indicated the poor performance of the closed loop.

\section{Direct synthesis PI controller design using}

\section{Genetic Algorithm}

In this work, Genetic Algorithm approaches are used to determine the optimized value of $\tau_{c}$ and it is used for the dynamic control of third order processes. From the comparison of many evolutionary algorithms, Genetic algorithms (GAs) are one of the most important methods [12]. It has been used to obtain the optimized parameters and it has been used with decent outcomes. It is optimized based on the search techniques. This control technique, the tuned parameter of PI controller is combined with the search algorithm based optimized parameters. This control strategy is applied to a third order processes and results show enhanced closed loop performance.

The optimized parameter is used to obtain the closed loop response of third order processes. The following steps are used to obtain the optimized parameter $\tau_{c}$ and it is obtained by using

ITAE performance index.

1. Construct a simulation model of the closed loop system with PI controller and process transfer function.

2. The parameter is optimized with an objective function.

3. Form MATLAB Optimization Toolbox, the optimized parameter is obtained with minimization of the objective function.

The Direct Synthesis method is used to tune the controller parameters of PI controller. These controller parameters are obtained with the process parameters and the introduced parameter $\tau_{c}$. The Genetic Algorithm is used to obtain the optimized parameter $\tau_{c}$. The parameters of PI controller are obtained with the optimized value of $\tau_{c}$. The obtained value is used in a closed loop system and simulated responses are obtained. The unit step response of the proposed controller is shown in Fig. 7 and Fig. 8.

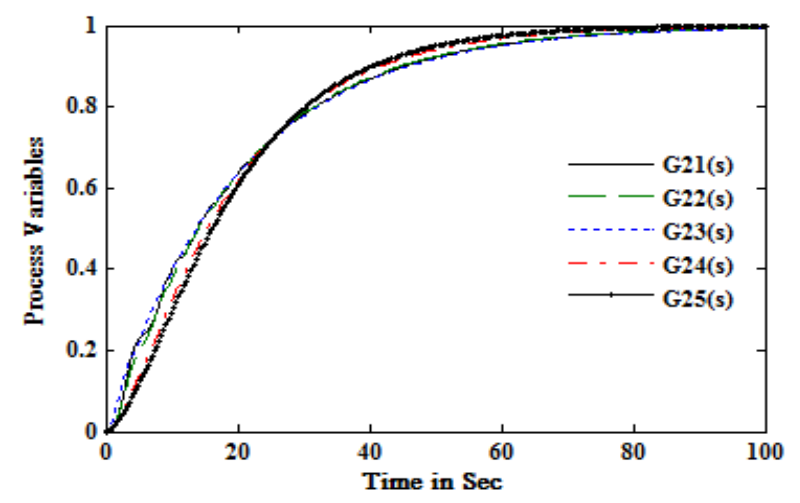

Fig. 7: Unit step response of PI controller with optimized parameter $\tau_{c}$

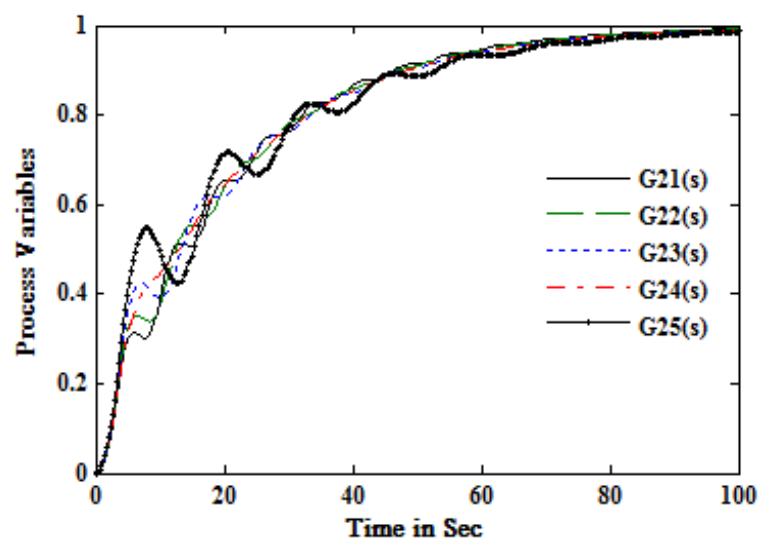

Fig. 8: Unit step response of PI controller with optimized parameter $\tau_{c}$

The second and third cases of third order processes are used for further analysis of this method. Fig. 7 and Fig. 8 have shown that, the closed loop responses of PI controller with optimized parameters. From the results, it revealed that the no peak overshoot in the closed loop response of third order processes. The process varia- 
ble is oscillates when using the controller parameters tuned by Direct Synthesis method. The oscillatory responses are reduced when compared to optimized parameter $\tau_{c}$ is used in PI controller. The peak overshoot in both categories of third order process is eliminated and this method is effectively controlled in the third order system. The optimized parameter $\tau_{c}$ based parameter of PI controller with is effectively controlled in third order system and it is also enhanced the control loop performance. The efficacy of the proposed controller is evaluated by controlling the different categories of third order transfer processes.

\section{Conclusions}

In this work, the direct synthesis PI controller is combined with the optimized parameter which is obtained by using Genetic Algorithm and it is used for control of third order processes. From the simulation results, the closed loop performance of PI controller for the control third order processes is delivered poor performance. The direct synthesis method, the PI controller is tuned with the process parameters and an introduced parameter. The closed loop responses are obtained for the third order system with the selection of small and large value of introduced parameter. It revealed that the small value introduced very poor performance and the selection of large value is enhanced the closed loop performance. In this study, the introduced parameter is optimized by using the Genetic Algorithm. It provides the superior closed loop performance for the control of third order processes without peak overshoot and process variable oscillatory. The effectiveness of the proposed optimized method is verified with different coefficients of two different categories of third order processes.

\section{References}

[1] Ramon Vilanova, Antonio Visioli, The Proportional-IntegralDerivative (PID) Controller, Wiley Encyclopedia of Electrica and Electronics Engineering, John Wiley and sons, 2017.

[2] J.G. Ziegler, N.B. Nichols, Optimum settings for automatic controllers, Transactions of the ASME, Vol.64, 1942, pp.759-768

[3] Cheng Zhao, Lei Guo, PID controller design for second order nonlinear uncertain systems, Science China Information Sciences, Springer, 2017.

[4] Hisatoshi Katsumata, Keiji Konishi, and Naoyuki Hara, Proportional-integral control of propagating wave segments in excitable media, Physical Review E, Vol. 95, 2017, pp. 042216 (1-7).

[5] Y. Eremenko, A. Glushchenko, V. Petrov, On PI-controller parameters adjustment for rolling mill drive current loop using neural tuner, Procedia Computer Science, Vol.103, 2017, pp. $355-$ 362.

[6] Dan Chen, Dale E. Seborg, PI/PID Controller Design Based on Direct Synthesis and Disturbance Rejection, Indian Engineering Chemistry Research, vol. 41, no. 19, 2002, pp. 4807-4822.

[7] Jyh-ChengJeng, A model-free direct synthesis method for PI/PID controller design based on disturbance rejection, Chemometrics and Intelligent Laboratory Systems, Vol.147, 2015, pp. 14-29.

[8] Naresh Kumari, Nitin Malik, A. N. Jha, Gaddam Mallesham, Design of PI Controller for Automatic Generation Control of Multi Area Interconnected Power System using Bacterial Foraging Optimization, International Journal of Engineering \& Technolgy, Vol. 8, No. 6, 2016, pp.2779-2786.

[9] E. Govinda Kumar, E. Gowthaman, Cascade PID-Lead Compensator Controller for Non-overshoot Time, Energy Procedia, Vol. 117, 2017, pp.708-715.

[10] E. Govinda Kumar, B. Mithunchakravarthi and N. Dhivya, Enhancement of PID Controller Performance for a Quadruple Tank Process with Minimum and Non-Minimum Phase Behaviors, Procedia Technology, Vol. 14, 2014, pp. 480-489.

[11] R. Kumar*, S.K. Singla, V. Chopra, Comparison among some well-known control scheme with different tuning methods, Journal of Applied Research and Technology, 2015, pp.409-415

[12] Omar M. Sallabi, Younis El-Hadded, An Improved Genetic Algorithm to Solve the Traveling Salesman Problem, World Academy of Science, Engineering and Technology, Vol.3, No.4, 2009, pp. 984-987.
[13] S.V. Manikanthan , T. Padmapriya "An enhanced distributed evolved node-b architecture in 5G tele-communications network" International Journal of Engineering \& Technology (UAE), Vol 7 Issues No (2.8) (2018) 248-254.March2018

[14] S.V.Manikanthan and V.Rama“'Optimal Performance of Key Predistribution Protocol In Wireless Sensor Networks" International Innovative Research Journal of Engineering and Technology ,ISSN NO: 2456-1983,Vol-2,Issue -Special -March 2017.

[15] T.Padmapriya, Ms. N. Dhivya, Ms U. Udhayamathi, "Minimizing Communication Cost In Wireless Sensor Networks To Avoid Packet Retransmission", International Innovative Research Journal of Engineering and Technology, Vol. 2, Special Issue, pp. $38-42$. 